\title{
Utilization of Superparamagnetic Iron Oxide Nanoparticles (SPIONs) Impregnated Activated Carbon for Removal of Hexavalent Chromium
}

\author{
Aisha Farhana $\mathbb{D},{ }^{1}$ A. Jenifer Selvarani $\mathbb{D}^{\mathbb{2}},{ }^{2}$ Antony V. Samrot $\mathbb{D}^{3},{ }^{3}$ Abdullah Alsrhani $\mathbb{D},{ }^{1}$ \\ P. Raji $\mathbb{C}^{2}{ }^{2}$ Chamarthy Sai Sahithya, ${ }^{2}$ P. J. Jane Cypriyana $\mathbb{1}^{\circ},{ }^{2}$ P. Senthilkumar, ${ }^{4}$ \\ Mok Pooi Ling, ${ }^{1,5,6}$ and Simon Yishak $\mathbb{1}^{7}$ \\ ${ }^{1}$ Department of Clinical Laboratory Sciences, College of Applied Medical Sciences, Jouf University, Sakaka, \\ P.O. Box 2014 Aljouf, Saudi Arabia \\ ${ }^{2}$ Department of Biotechnology, School of Bio and Chemical Engineering, Sathyabama Institute of Science and Technology, Chennai, \\ Tamil Nadu 600119, India \\ ${ }^{3}$ School of Bioscience, Faculty of Medicine, Bioscience and Nursing, MAHSA University, Jenjarom, 42610 Selangor, Malaysia \\ ${ }^{4}$ Department of Chemical Engineering, School of Bio and Chemical Engineering, Sathyabama Institute of Science and Technology, \\ Chennai, Tamil Nadu 600119, India \\ ${ }^{5}$ Department of Biomedical Sciences, Faculty of Medicine and Health Sciences, Universiti Putra Malaysia, 43400 UPM Serdang, \\ Selangor, Malaysia \\ ${ }^{6}$ Genetics and Regenerative Medicine Group, Faculty of Medicine and Health Sciences, Universiti Putra Malaysia, \\ 43400 UPM Serdang, Selangor, Malaysia \\ ${ }^{7}$ College of Engineering and Agro-Industrial Technolgy, Sawla Campus, Arba Minch University, Ethiopia
}

Correspondence should be addressed to Antony V. Samrot; antonysamrot@gmail.com and Simon Yishak; simon.yishak@amu.edu.et

Received 8 November 2021; Accepted 7 December 2021; Published 18 January 2022

Academic Editor: Domenico Acierno

Copyright (C) 2022 Aisha Farhana et al. This is an open access article distributed under the Creative Commons Attribution License, which permits unrestricted use, distribution, and reproduction in any medium, provided the original work is properly cited.

\begin{abstract}
Chromium (Cr) is a toxic heavy metal present in industrial effluent which could cause degenerative diseases on ingestion. Therefore, elimination of $\mathrm{Cr}$ from contaminated water becomes essential to preserve and sustain the quality of life. In this study, superparamagnetic iron oxide nanoparticles (SPIONs) were impregnated on activated carbon and checked for enhanced removal of $\mathrm{Cr}(\mathrm{VI})$. Thus, granular activated carbon (N-GAC) of mesh size $8 * 20$ was impregnated with SPIONs to produce SPIONs impregnated activated carbon (Sp-GAC) and characterized using UV-VIS spectrophotometer, FT-IR, SEM-EDX, XRD, and VSM. Sp-GAC was found to be possessing superparamagnetic behavior, and it was used in batch adsorption study where the adsorption parameters like $\mathrm{pH}$, concentration of adsorbent, and adsorbent-adsorbate were optimized. It was found that $\mathrm{Cr}(\mathrm{VI})$ adsorption was predominant at acidic $\mathrm{pH}(\mathrm{pH} 3)$ for both cases; moreover, N-GAC showed better adsorption comparatively. Both the N-GAC and Sp-GAC adsorption were found to be obeying to Langmuir.
\end{abstract}

\section{Introduction}

Chromium heavy metal ions are reported as one of the common environmental contaminants of land and natural water bodies $[1,2]$. Over the past decades of rapid industrialization, the level of chromium heavy metal ion in environment has increased to an alarming rate, effectively penetrating the lower aquifers $[3,4]$. Chromium salts are used by various industries for paints production, wood preservation, cement processing, metallurgy, electroplating, paper production, and majorly for leather tanning $[5,6]$. In most cases, the effluents are directly or indirectly discharged into natural 
water bodies. Chromium heavy metal exists in varied valence or oxidation states such as $\mathrm{Cr}(0), \mathrm{Cr}(\mathrm{III})$, and $\mathrm{Cr}(\mathrm{VI})$ [7], of which hexavalent chromium $\mathrm{Cr}(\mathrm{VI})$ are more noxious and causes mutagenesis in plant, animals, and humans [8-10]. Stohs and Bagchi [11] have reported that $\mathrm{Cr}(\mathrm{VI})$ formed reactive oxygen species such as superoxide ion, hydrogen peroxide, and hydroxyl radical on reacting with biological reductant like thiols and ascorbate, eventually causing cellular DNA damage due to oxidative stress. And also, $\mathrm{Cr}(\mathrm{VI})$ is found to easily enter the cellular membrane by mimicking the isoelectric and isostructural passages of $\mathrm{SO}_{42}{ }^{-}$and $\mathrm{HPO}_{42}-[12]$. Hence, chromium removal from contaminated waters must be resolved with deep concern. Chemical precipitation, adsorption, electrochemical precipitation, ion exchange, and reverse osmosis are the widely followed techniques in industries to eliminate $\mathrm{Cr}$ from treated waters [13-17]. Of them, the most easy and feasible technique is adsorption, where the adsorbate $(\mathrm{Cr})$ is confined over the adsorbent by electrostatic or ionic interaction [18]. The other techniques have few limitations such as need of auxiliary chemical agents, expensive installation, energy demands, and management of reduced waste and byproducts [19].

Recent efforts in nanotechnology have proved that nanomaterials can also serve as good adsorbents for $\mathrm{Cr}(\mathrm{VI})$. The nanostructure offers increased interaction due to increased surface area. Silver nanoparticles are also not much effective when they are used for removal of heavy metals [20]. Parlayici et al. [21] produced nanocarbon tubes (CNTs) installed with activated carbon to remove $\mathrm{Cr}(\mathrm{VI})$. According to their report, activated carbon-based nanocarbon tubes showed highest adsorption capacity to $113.29 \mathrm{mg} / \mathrm{g}$ than all sphere forms and the adsorption was described with Langmuir isotherm. Iron oxide nanoparticles like SPIONs (superparamagnetic iron oxide nanoparticles) have drawn the attention of many researchers as they can be easily manipulated by externally applied magnetic field. Apart from their wide-ranging applications in targeted drug delivery [22, 23], hyperthermia [24], theragnostic [25, 26], and imaging [27], SPIONs are also employed for removal of heavy metal ions [28]. CNTs impregnated with $10 \%$ of iron oxide and aluminium oxides were found to remove $\mathrm{Cr}(\mathrm{VI})$ to $100 \%$ when the treating solution was maintained at $\mathrm{pH} 6$. It was found that the performance of impregnated CNTs was significantly higher than the raw CNTs. The adsorption under parameters like $\mathrm{pH}$, agitation time, absorbent concentration, and contact time was also checked [29]. Likewise Jain and his coworkers [30] came up with a nanocomposite of activated carbon and $\mathrm{Fe} 3 \mathrm{O} 4$. Its adsorption capacity was checked against $\mathrm{Cr}(\mathrm{VI})$, $\mathrm{Cu}(\mathrm{II})$, and $\mathrm{Cd}(\mathrm{II})$ ions where the nanocomposite showed better $\mathrm{Cr}(\mathrm{VI})$ removal at acidic $\mathrm{pH} 2$ and $\mathrm{pH} 6$ as the optimal $\mathrm{pH}$ for $\mathrm{Cu}(\mathrm{II})$ and $\mathrm{Cd}(\mathrm{II})$ ions. They further explained the adsorption by Langmuir isotherm as the best fit model and stated that the materials possessed reusability to four adsorption-desorption cycles.

According to our earlier report [31], chitosan-coated SPIONs at $10 \mathrm{~g} / \mathrm{L}$ were found to remove $\mathrm{Cr}(\mathrm{VI})$ of $50 \mathrm{ppm}$ to $95 \%$ at acidic $\mathrm{pH}$. It was also observed that adsorption of $\mathrm{Cr}(\mathrm{VI})$ was greatly influenced by adsorbent concentration, interaction time, and $\mathrm{pH}$. Here, the concept of impregnating SPIONs onto activated carbon was based on the fact that activated carbon is the most commonly used adsorbent material to remove pollutants from water in both industrial and domestic water purifiers. Therefore, commercially available activated carbon was used for impregnation. SPIONs impregnated activated carbon were synthesized by coprecipitation method and characterized by Fourier Transform-Infrared Spectroscopy (FT-IR), Scanning Electron Microscopy-Energy Dispersive X-ray (SEM-EDX), X-ray Diffraction (XRD), and Vibrating Sample Magnetometer (VSM). These impregnated carbon were subjugated for $\mathrm{Cr}(\mathrm{VI})$ adsorption, and it was finally evaluated using adsorption isotherms like Langmuir, Freundlich, and Temkin.

\section{Materials and Methods}

2.1. Materials and Reagents. The following chemicals and reagents were purchased at analytical grade quality-ferrous chloride (LOBACHEMIE), anhydrous ferric chloride (LOBACHEMIE), ammonium solution (SRL), sodium hydroxide (SRL), hydrochloric acid, acetic acid (RAMKEM), ammonium ferrous sulphate (NH4)2.Fe(SO4)2.6H2O (SRL), diphenyl carbazide (SRL), potassium dichromate (SRL), ascorbic acid (SRL), sodium acetate (anhydrous), and methanol (SRL). The entire study was carried out using nitrogen purged Millipore water.

2.2. Synthesis of SPIONs. Iron oxide nanoparticles were synthesized by chemical coprecipitation. $100 \mathrm{~mL}$ of $1 \mathrm{M}$ ferric chloride solution and $100 \mathrm{~mL}$ of $3 \mathrm{M}$ ferrous chloride solution were prepared separately in nitrogen purged Millipore water. Equal volumes $(50 \mathrm{~mL})$ of the prepared precursor solutions were brought into suspension by magnetic agitation for $20 \mathrm{~min}$. Then, the precursor suspension was heated to $60^{\circ} \mathrm{C}$. This heat energy is assumed to accelerate the reduction of Fe ions. While heating the precursor solution at $60^{\circ} \mathrm{C}$, $75 \mathrm{~mL}$ of freshly prepared $8 \mathrm{M} \mathrm{NaOH}$ and $25 \mathrm{~mL}$ of ammonia solution were added in alternative drops with vigorous mechanical stirring. The addition of reducing agent turned the precursor solution into black precipitate and increased the $\mathrm{pH}$ of the mixture. The high alkali $\mathrm{pH}$ was neutralized to $\mathrm{pH} 7$ with $1 \mathrm{~N} \mathrm{HCl}$ washing. Later, the black precipitate which is superparamagnetic iron oxide nanoparticle (SPION) was settled down and collected by applying magnetic field. It was then washed with nitrogen purged Millipore water for several times to remove impurities and then lyophilized [31].

2.3. Preparation of SPIONs Impregnated Activated Carbon. Granular activated carbon (N-GAC) of mesh size $8 * 20$ was bought commercially and rinsed for multiple times with distilled water until the spent water becomes clear. This removed the carbon dust and impurities present. The washed activated carbon was dried on a filter paper and then heated to $80^{\circ} \mathrm{C}$ to remove moisture. $40 \mathrm{~g}$ activated carbon (N-GAC) was added with the iron precursor solution and subjected for SPION production as described above in the way to incorporate SPIONs. Then, it was heated to $60^{\circ} \mathrm{C}$ 
and stirred by magnetic agitation for $20 \mathrm{~min}$. By doing so, the carbon and the pores within would get completely wet with the iron ions. Then, the reducing agents $\mathrm{NaOH}$ and ammonia were added simultaneously in drops with vigorous mechanical stirring. This leads to formation of SPIONs onto the surface as well as within the pore of the activated carbon. Thus, the carbon was impregnated with SPIONs. Finally, the carbon was filtered out using a nylon mesh filter and washed with Millipore water until the filtrate becomes clear and neutral ( $\mathrm{pH} 7$ ). The granular activated carbon impregnated with SPIONs (Sp-GAC) was used after freeze drying.

\subsection{Characterization of SPIONs and SPIONs Impregnated} Activated Carbon. SPIONs, N-GAC, and Sp-GAC were characterized by performing the following analysis: FT-IR (IR affinity-1S, Shimadzu, Japan), Scanning Electron Microscopy (SEM) (Carl Zeiss, Germany), Energy Dispersive X-ray (EDX) analysis, and XRD (Rigaku, Tokyo), where the SPIONs and Sp-GAC were subjected for Vibrating Sample Magnetometer (VSM) with a maximum magnetic field of $2.5 \mathrm{~T}$ and dynamic moment range of $1 \times 10 e-6$ emu-10e 3 emu (Lakeshore, USA, Model 7407).

\subsection{Quantification of Iron Impregnated onto Activated Carbon}

2.5.1. Establishment of Standard Iron Curve. $3.511 \mathrm{~g}$ of ammonium ferrous sulphate $\left(\mathrm{NH}_{4}\right)$ 2. $\mathrm{Fe}\left(\mathrm{SO}_{4}\right) 2.6 \mathrm{H} 2 \mathrm{O}$ (which contains $500 \mathrm{mg}$ of $\mathrm{Fe}$ ) in $1 \mathrm{~L}$ of nitrogen purged Millipore water was used as standard iron stock solution for $500 \mathrm{ppm}$. On diluting the stock, different parts per million (ppm) of iron solution was prepared and photometrically detected the total iron in accordance with Changzhao et al. [32]. Standard was prepared and made up to $0.5 \mathrm{~mL}$ with water and then with $6.8 \mathrm{~mL}$ of Millipore water, $0.2 \mathrm{~mL}$ of ascorbic acid $(5 \mathrm{~g}$ in $50 \mathrm{~mL}$ ), and $2 \mathrm{~mL}$ of sodium acetate buffer ( $16.4 \mathrm{~g}$ of sodium acetate in $24 \%$ acetic acid). Then, the reaction mixture was pipetted with $1 \mathrm{ml}$ of 1,4 phenanthroline reagent $(0.1 \%)$ and vortexed. The absorbance was photometrically read at $510 \mathrm{~nm}$. A graph was plotted having the concentration in ppm as $X$-axis and absorbance as $Y$-axis.

2.5.2. Estimation of Total Iron Impregnated on activated carbon Using 1,4 Phenanthroline. To detect total iron impregnated on activated carbon, different concentrations of each sample (N-GAC and Sp-GAC) such as $10 \mathrm{mg}$, $30 \mathrm{mg}$, and $50 \mathrm{mg}$ were treated with $10 \mathrm{~mL}$ of $10 \% \mathrm{H}_{2} \mathrm{SO}_{4}$ for $24 \mathrm{~h}$. After acid digestion, $0.5 \mathrm{~mL}$ of solution from each sample was processed (as prescribed above) for photometric detection with 1,4 phenanthroline at $510 \mathrm{~nm}$ and concentration was calculated from standard graph.

2.6. Preparation of $\mathrm{Cr}(V I)$ Solution. For the study, different ppm concentrations of chromium were prepared using potassium dichromate as the chromium salt. $0.14 \mathrm{~g}$ of potassium dichromate $\left(\mathrm{K}_{2} \mathrm{Cr}_{2} \mathrm{O}_{7}\right)$ in $100 \mathrm{~mL}$ of Millipore water corresponds to $500 \mathrm{ppm}$; further dilution was done to obtain 5 ppm of chromium solution (adsorbate).
2.6.1. Establishment of Standard Cr(VI) Curve. Different ppm concentrations of chromium solution were prepared by diluting the stock solution. Diphenyl carbazide (DPC) is a compound that binds exclusively to hexavalent chromium ions; and therefore, it acts as an indicator of hexavalent chromium. On binding with hexavalent chromium ions, the reacting mixture turns reddish violet colour [33, 34]. An aliquot of $\mathrm{Cr}$ solution from each dilution was reacted with DPC reagent for colour development. Then, it was spectrophotometrically read at $540 \mathrm{~nm}$. A graph was plotted having ppm in $X$-axis vs. $O D$ at $540 \mathrm{~nm}$ in $Y$-axis.

2.7. Adsorption Study in Batch Experimental System. Chromium removal by different adsorbents was studied in batch system, and the parameters like concentration of adsorbent, concentration of adsorbate, and $\mathrm{pH}$ were optimized. Here, the adsorption study was considered for a particular period, i.e., 0th $\mathrm{min}$ to 120 th $\mathrm{min}$. All the batch setups were placed on rotatory shaker at $200 \mathrm{rpm}$ in room temperature.

2.7.1. Effect of $p H$. To identify the activity of adsorbents against $\mathrm{Cr}$ ions at different $\mathrm{pH}$, the adsorption was checked at a $\mathrm{pH}$ range of $3,5,7,9,11$, and $13.1 \mathrm{M} \mathrm{HCl}$ and $1 \mathrm{M}$ $\mathrm{NaOH}$ prepared in Millipore water were used to adjust the $\mathrm{pH}$ of the $\mathrm{Cr}(\mathrm{VI})$ solution to a respective range. To each flask with $100 \mathrm{ml}$ of $5 \mathrm{ppm} \mathrm{Cr}(\mathrm{VI})$ at different $\mathrm{pH}, 10 \mathrm{~g} / \mathrm{L}$ of $\mathrm{N}$ GAC and Sp-GAC was added separately and placed in shaker at $200 \mathrm{rpm}$ for $2 \mathrm{~h}$. After incubation, the supernatant from each setup was spectrophotometrically read at $540 \mathrm{~nm}$. The final concentration of $\mathrm{Cr}$ in the solution was calibrated from the standard curve. \% removal was calculated from the below formula:

$\%$ removal $=\frac{(\text { initial concentration }- \text { final concentration })}{\text { initial concentration }} \times 100$.

To check the concentration of iron leached out from the adsorbent material, $0.5 \mathrm{~mL}$ of the supernatant was acid digested with $0.2 \mathrm{ml}$ of $\mathrm{H}_{2} \mathrm{SO}_{4}$ and later, it was tagged with the reagent 1,4 phenanthroline by following the above described method in Section 2.5.1. The iron released was estimated from the standard. The final data were made into a graph with $X$-axis as $\mathrm{pH}$, primary $Y$-axis as \% removal, and secondary $Y$-axis as iron leached (ppm).

2.7.2. Optimization of Adsorbent Concentration. Different concentrations $(1 \mathrm{~g} / \mathrm{L}$ to $10 \mathrm{~g} / \mathrm{L})$ of the adsorbents N-GAC and Sp-GAC were added to $100 \mathrm{ml}$ of $5 \mathrm{ppm} \mathrm{Cr}(\mathrm{VI})$ solution at optimal $\mathrm{pH}$ (from above results). It was allowed to react for $2 \mathrm{~h}$ by constantly shaking at $200 \mathrm{rpm}$. Later, an aliquot of treated solution from each set was processed for DPC tagging and read at $540 \mathrm{~nm}$. \% removal of $\mathrm{Cr}$ and iron leached into the reaction mixture was also estimated from standard curve. A graph was plotted with adsorbate concentration as $X$-axis, \% removal as primary $Y$-axis, and iron leached as secondary $Y$-axis.

2.7.3. Optimization of Adsorbate-Adsorbent Concentration. Here, the efficiency of the adsorbents N-GAC and Sp-GAC 
at $10 \mathrm{~g} / \mathrm{L}$ in removal of maximum concentration of adsorbate was determined. It was performed with a fixed concentration of adsorbent against varied concentration of adsorbate. $10 \mathrm{~g} / \mathrm{L}$ of N-GAC was added to each of $100 \mathrm{~mL}$ of $\mathrm{Cr}(\mathrm{VI})$ solution at $1 \mathrm{ppm}, 5 \mathrm{ppm}, 10 \mathrm{ppm}, 20 \mathrm{ppm}, 40 \mathrm{ppm}, 80 \mathrm{ppm}, 160 \mathrm{ppm}$, and $320 \mathrm{ppm}$. All the different concentrations of adsorbate were prepared at the optimal $\mathrm{pH}$. Similar reaction setup was made for the adsorbent, Sp-GAC. They were kept on shaker at $200 \mathrm{rpm}$ for $2 \mathrm{~h}$. After treatment, the \% removal of Cr was estimated spectrophotometrically by the DPC method $(540 \mathrm{~nm})$. Parallelly, $0.5 \mathrm{ml}$ of each of the supernatant was reacted with 1,4 phenanthroline after acid digestion to quantify (in $\mathrm{ppm}$ ) the concentration of iron leached from the adsorbents. The graph was plotted between $\%$ removal ( $X$-axis), adsorbate concentration (primary $Y$-axis), and iron leached (secondary $Y$-axis).

2.8. Adsorption Isotherm of Batch System. The mechanism of adsorption of adsorbate onto the adsorbent can be understood from adsorption isotherms. Having all the parameters optimized, the resultant data was used to bring up the following isotherm models, namely, Langmuir (1/qe vs. 1/Ce), Freundlich (ln qe vs. In Ce), and Temkin (qe vs. ln Ce). The isotherms were plotted by calculating $\mathrm{Ce}$, qe, $1 / \mathrm{Ce}$, ln Ce, 1/qe, and ln qe values [35].

$$
\mathrm{qe}=(\mathrm{Ci}-\mathrm{Ce}) \frac{V}{m}
$$

where qe is the adsorption capacity at equilibrium, $\mathrm{Ci}$ is the initial concentration, $\mathrm{Ce}$ is the final concentration, $V$ is volume of the adsorbate, and $m$ is mass of the adsorbent.

\section{Results and Discussions}

\subsection{Characterization of SPIONs}

3.1.1. UV-VIS Spectroscopy. The optical property of the synthesized SPIONs can be described from UV-VIS spectroscopy. Figure 1 shows the optical adsorption spectra of synthesized iron oxide nanoparticles at neutral $\mathrm{pH}$. The surface plasmon resonance (SPR) of SPIONs was observed as a broad peak in the UV region $(250 \mathrm{~nm}-300 \mathrm{~nm})$ which signifies the characteristic adsorption spectral range of iron oxide nanoparticles [36]. The adsorption maxima for the synthesized particles were recorded at $294 \mathrm{~nm}$. The spectra were more analogous to previous reports [31, 37]. Samrot et al. [38] reported SPIONs to show absorption maxima from $420 \mathrm{~nm}$, where here too an absorption maxima was found around $490 \mathrm{~nm}$.

3.1.2. Fourier Transform-Infrared Spectroscopy. The FT-IR spectrum of SPIONs is shown in Figure 2. The spectra clearly show IR adsorption bands in the low-frequency regions in the range of $487 \mathrm{~cm}^{-1}$ and $569 \mathrm{~cm}^{-1}$ which represents the stretching vibrations of $\mathrm{Fe}-\mathrm{O}-\mathrm{Fe}$ bond stretching vibration of tetrahedral sites of spinel structure of the synthesis magnetic nanoparticles [39-42]. Presence of other minor bands may be attributed to adsorbed organic mole-

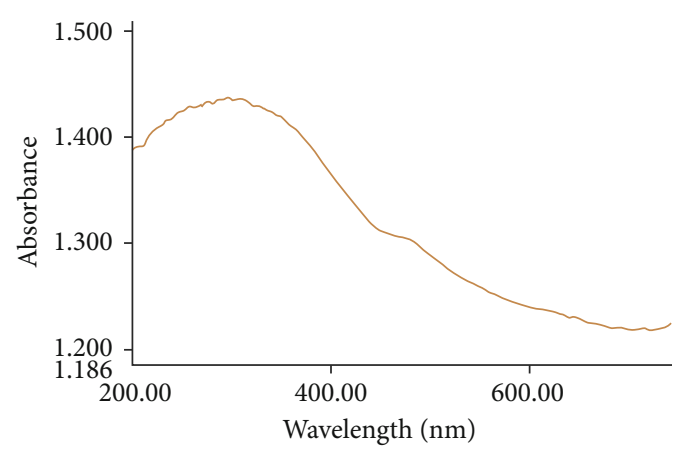

FIGURE 1: UV-VIS spectroscopy of SPIONs.

cules. Thus, the synthesized SPIONs are affirmed to contain $\mathrm{Fe}-\mathrm{O}$ bond from infrared adsorption spectra.

3.1.3. Scanning Electron Microscopy-Energy Dispersive $X$ Ray. From Figure 3(a), the particle size was between $23 \mathrm{~nm}$ and $35 \mathrm{~nm}$. The overall morphology of the particles was observed to be uniform and spherical with slight aggregation. As pristine samples, iron oxide nanoparticles tend to aggregate due to its high magnetic moment. Here, the slight aggregation may be because of the prevailing magnetic moment within the particle [43]. This can be prevented by coating SPIONs with detergents, biopolymer, and other materials [44]. In EDX (Figure 3(b) and Table 1), the presence of $\mathrm{Fe}$ and $\mathrm{O}$ was spotted with intense high peaks. Furthermore, this confirmed the presence of elementary components $\mathrm{Fe}$ and $\mathrm{O}$ in the prepared iron oxide nanoparticles.

3.1.4. X-Ray Diffraction Spectroscopy. X-ray diffractogram of synthesized iron oxide nanoparticles produced sharp characteristic peaks for magnetite nanoparticles with high degree crystallinity (Figure 4 ). The recorded $2 \theta$ peaks at corresponding degrees $30.47^{\circ}, 35.81^{\circ}, 57.35^{\circ}$, and $62.97^{\circ}$ corresponded to planes (220), (311), (511), and (440) referred to magnetite nanoparticle (JCPDS card no. 85-1436) [45]. Comparable XRD pattern was stated by Sruthi et al. [44]. By applying the below Scherer equation, the crystallite size was calculated from the diffraction peak with highest intensity.

$$
D=\frac{(K \lambda)}{(\beta \operatorname{Cos} \Theta)},
$$

where variable $D$ is crystal size $(\mathrm{nm}), K$ is lattice constant (0.98), $\lambda$ is wavelength $(0.154 \mathrm{~nm}), \beta$ is Full Width at Half Maximum (FWHM) of the sharp peaks, and $\theta$ is the Bragg angle. The high intensity peak at $35.81^{\circ}$ was a retort to crystallite of size $16.43 \mathrm{~nm}$, and the average crystallite size was determined as $14.22 \mathrm{~nm}$.

3.1.5. Vibrating Sample Magnetometer. VSM was recorded under applied magnetic field between $\pm 15 \mathrm{kOe}$ at room temperature (RT). This technique helps in deducing the magnetization power of the synthesized iron oxide nanoparticles. The magnetization power was found to increase sharply around the origin, and this was typical of superparamagnetism (Figure 5). Chellappan et al. [46] reported $2.4 \mathrm{emu} / \mathrm{g}$ for 


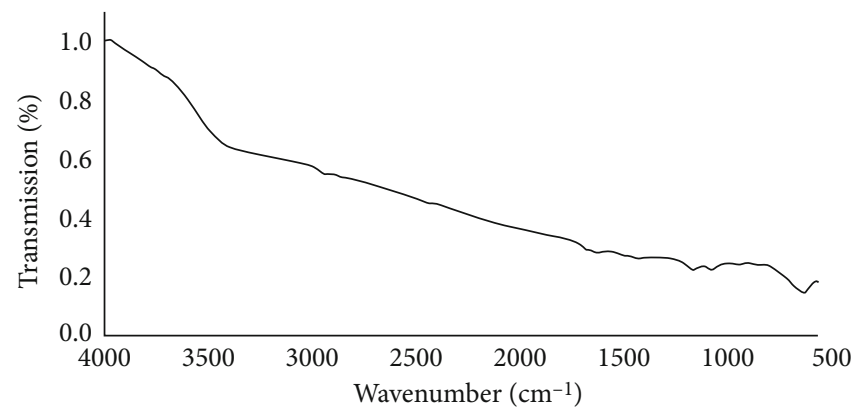

FIGURE 2: Fourier Transform-Infrared Spectroscopy (FT-IR) of SPIONs.

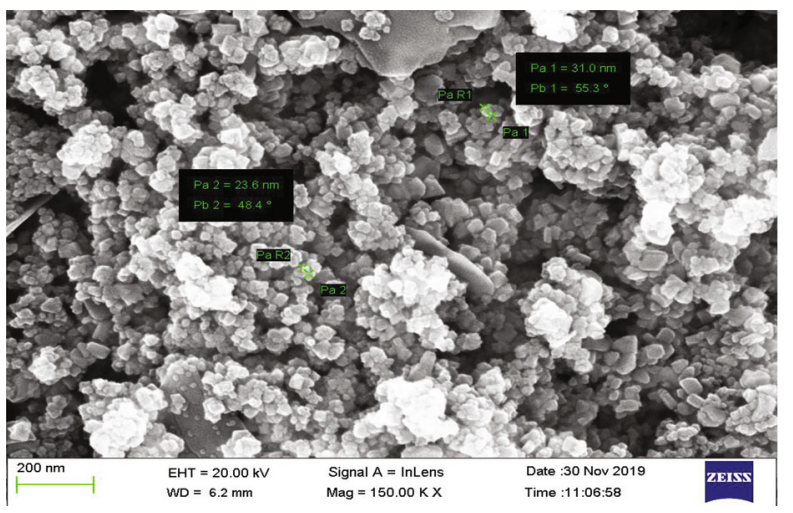

(a)

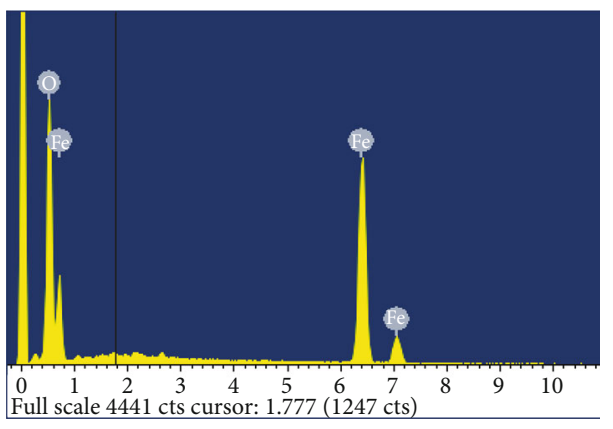

(b)

Figure 3: (a) Scanning Electron Microscopy. (b) Energy Dispersive X-ray (SEM-EDX) of SPIONs.

TABle 1: Atomic percentage and weight percentage of the elemental composition present in SPIONs.

\begin{tabular}{lcc}
\hline Element & Weight\% & Atomic\% \\
\hline O K & 36.71 & 66.94 \\
Fe K & 63.29 & 33.06 \\
Totals & 100.00 & \\
\hline
\end{tabular}

magnetite produced using $5 \mathrm{M} \mathrm{NaOH}$ as reducing agent. The produced iron oxide nanoparticles responded with maximum magnetization (Ms) of $88.22 \mathrm{emu} / \mathrm{g}$ at $15 \mathrm{kOe}$. Coercivity field value and remnant magnetization $(\mathrm{Mr})$ were recorded at negligible magnitudes as $124.51 \mathrm{Oe}$ and $12.7 \mathrm{emu} / \mathrm{g}$, respectively. Presence of hysteresis in SPIONs was found by Prijic et al. [47] with zero coercivity, and it was used to treat malignant cells [47]. Hysteresis loop forms when the sample retained a residual magnetic moment in the absence of externally applied field [48]. Baykal et al. [49] produced iron oxide nanoparticles of size $12 \mathrm{~nm}$ by chemical method using the same reducing agent $(\mathrm{NaOH})$ and reported the superparamagnetic behaviour of his nanoparticles via VSM spectra with no hysteresis loop.

\subsection{Characterization of SPIONs Impregnated Activated Carbon}

3.2.1. Fourier Transform-Infrared Spectroscopy. Figure 6 depicts the FT-IR spectra of N-GAC and Sp-GAC. The IR

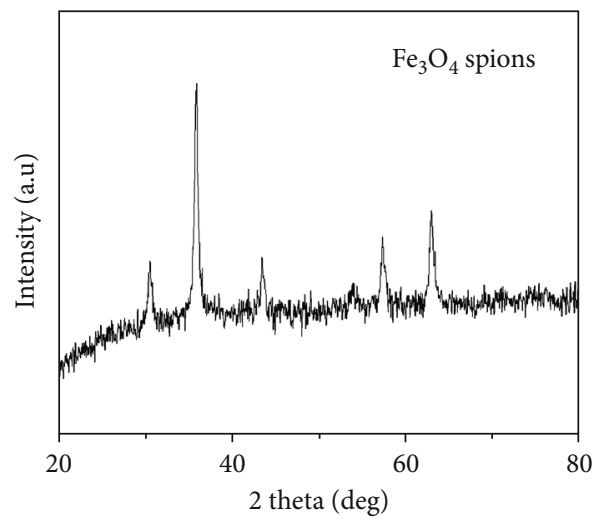

FIgURE 4: X-ray Diffraction (XRD) of SPIONs.

spectra of N-GAC showed peaks at $2883 \mathrm{~cm}^{-1}$ and $1570 \mathrm{~cm}^{-1}$ and $\mathrm{Sp}-\mathrm{GAC}$ at $1571 \mathrm{~cm}^{-1}, 1211 \mathrm{~cm}^{-1}$, and near $550 \mathrm{~cm}^{-1}$. The peak at $1570 \mathrm{~cm}^{-1}$ corresponds $\mathrm{C}=\mathrm{O}$ stretching [50]. Sp-GAC showed a major IR shift in the lowfrequency region around $510 \mathrm{~cm}^{-1}-570 \mathrm{~cm}^{-1}$. This is the characteristic vibration of $\mathrm{Fe}-\mathrm{O}-\mathrm{Fe}$ from iron oxide nanoparticles [51]. Therefore, this stated the successful impregnation of iron oxide onto Sp-GAC.

3.2.2. Scanning Electron Microscopy-Energy Dispersive X-Ray. Though granular size of carbon was already known, SEM 


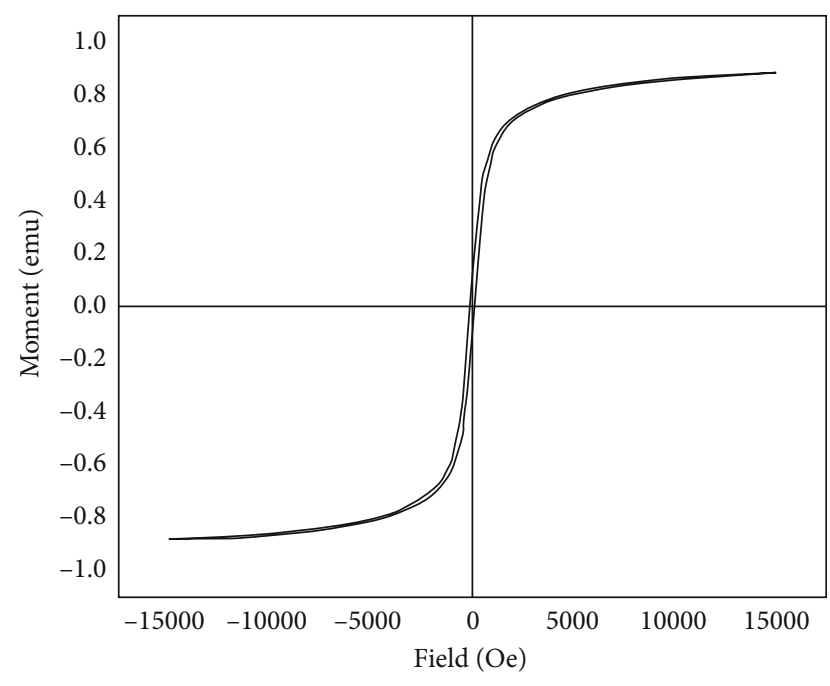

FIGURE 5: Vibrating Sample Magnetometer (VSM) of SPIONs.

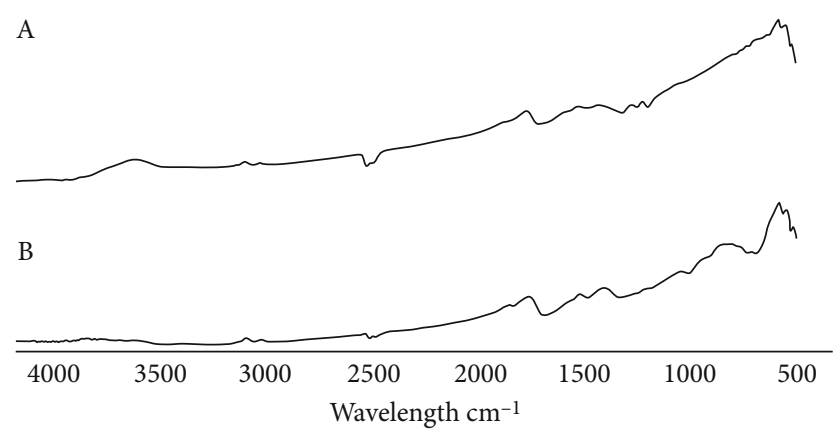

Figure 6: FT-IR. (a) Naked granular activated carbon (N-GAC) and (b) SPIONs impregnated granular activated carbon (Sp-GAC).

revealed the surface topography of the naked activated carbon (N-GAC) as well as the SPIONs impregnated activated carbon (Sp-GAC). Figure 7(a) shows the SEM micrograph of N-GAC. By observing N-GAC under SEM, it was found that the surface of the granules was nonuniform where each granule possessed irregular frame. SEM micrograph showed the porous structure of carbon. After impregnating (Sp-GAC), the surface was evenly distributed with SPIONs (Figure 7(b)). SPIONs formed on the surface of Sp-GAC were spherical with similar in morphology to SPIONs in Figure 3. This expresses that iron ion enriched surfaces of carbon act as nucleation site for iron oxide formation. However, the impregnated SPION size was bigger comparatively in the range of $50 \mathrm{~nm}-70 \mathrm{~nm}$, might because of agglomeration of nanoparticles. EDX results confirmed the elemental source of each adsorbents. N-GAC produced high intense carbon peaks (Figure 7(a)). Sp-GAC responded with peaks of $\mathrm{C}, \mathrm{Fe}$, and $\mathrm{O}$ which further confirms the presence of iron oxide (Figure 7(b)). The intensity of $\mathrm{C}$ peak was much reduced in Sp-GAC since the surface of carbon was concealed by iron oxides. Samrot et al. [38] reported SPIONs produced using $\mathrm{NaOH}$ and ammonia solution as reducing agent to show size around $41 \mathrm{~nm}$.

3.2.3. X-Ray Diffraction Spectroscopy. N-GAC showed peaks at $2 \theta=25,45$ corresponding to the planes (002) and (100) of graphitic crystallites of carbon (Figures $8(a)$ and $8(b)$ ). In terms of structure, the activated carbon can be termed as more amorphous from XRD spectra. Rajendran et al. [52] also reported similar XRD records for the activated carbon produced from agricultural waste. Activated carbon produced from cocoa shell were also reported to be amorphous in nature by Tejada et al. [53]. The XRD pattern of activated carbon after impregnation (Sp-GAC) was found to have peaks at $30.47^{\circ}, 35.81^{\circ}$, and $62.97^{\circ}$ which are characteristics of SPIONs and looked to be amorphic in structure as carbon was there (Figure 4).

3.2.4. Vibrating Sample Magnetometer. The M-H at RT spectra revealed the superparamagnetic behaviour of Sp-GAC (Figure 9). Sp-GAC showed saturation magnetization (Ms) of about $53.22 \mathrm{emu} / \mathrm{g}$ with coercivity at $144.18 \mathrm{Oe}$ and remnant magnetization (Mr) at $9.04 \mathrm{emu} / \mathrm{g}$. Although Sp-GAC expressed less magnetization (Ms) compared to SPIONs (Figure 5), it maintained reduced remanence effect throughout the analysis. This was apparent with absence of hysteresis loop. Hence, this proves that activated carbon possess superparamagnetism on impregnating with iron oxide nanoparticles. Gallios and his coworkers [54] produced magnetic activated carbon for arsenic removal and checked its magnetic behaviour in VSM. Magnetization ( $\mathrm{Ms}=0.35 \mathrm{emu} \mathrm{g}^{-1}$ ) of impregnated carbon was higher than the unimpregnated carbon $\left(\mathrm{Ms}=0.1 \mathrm{emug}^{-1}\right)$ (result not shown here)", and its superparamagnetic magnetization curve was more analogous to the VSM of SPIONs.

3.3. Quantification of Iron Impregnated onto Activated Carbon. A standard graph of Fe with $R^{2}=0.988$ was established for ammonium ferrous sulphate salt following the abovesaid method. The acid digested samples (obtained from N-GAC and Sp-GAC) were treated with 1,4 phenanthroline as stated in the above method, and the concentration of iron was identified against the standard graph (Figure 10). It showed that the concentration of iron was directly proportional to concentration of adsorbents, even the commercial activated carbon (N-GAC) contained iron within it which should be the iron contamination from carbon processing or in the source itself. $10 \mathrm{mg}, 20 \mathrm{mg}$, and $30 \mathrm{mg}$ of Sp-GAC contained $0.052 \mu \mathrm{g} / \mathrm{mg}, 0.073 \mu \mathrm{g} / \mathrm{mg}$, and $0.143 \mu \mathrm{g} / \mathrm{mg}$ of iron, respectively. Szpak et al. [55] have also employed the above method (using 1,4 phenanthroline) to quantify the iron concentration in SPIONs for relaxometry analysis. Likewise, Górka et al. [56] also estimated the total iron content of his SPIONs as $0.871 \mathrm{mg} / \mathrm{ml}$ using 1,4 phenanthroline reagent.

\subsection{Batch Adsorption Studies}

3.4.1. Adsorption at various $\mathrm{pH}$. Identification of optimal $\mathrm{pH}$ is important for adsorption study because ionic charge of the absorbents in most cases relies on the $\mathrm{pH}$ of the reacting solution. This trial was carried out by treating fixed concentration of adsorbent with adsorbate solution at varied $\mathrm{pH}$ (Figure 11). Adsorption was significantly higher in the acidic $\mathrm{pH}$ range with maximal $\mathrm{Cr}$ removal at $\mathrm{pH} 3$. Despite a metal ion, chromium will exist as anionic chromates (oxidation states) in aqueous solution. $\mathrm{Cr}(\mathrm{VI})$ takes the anionic form 

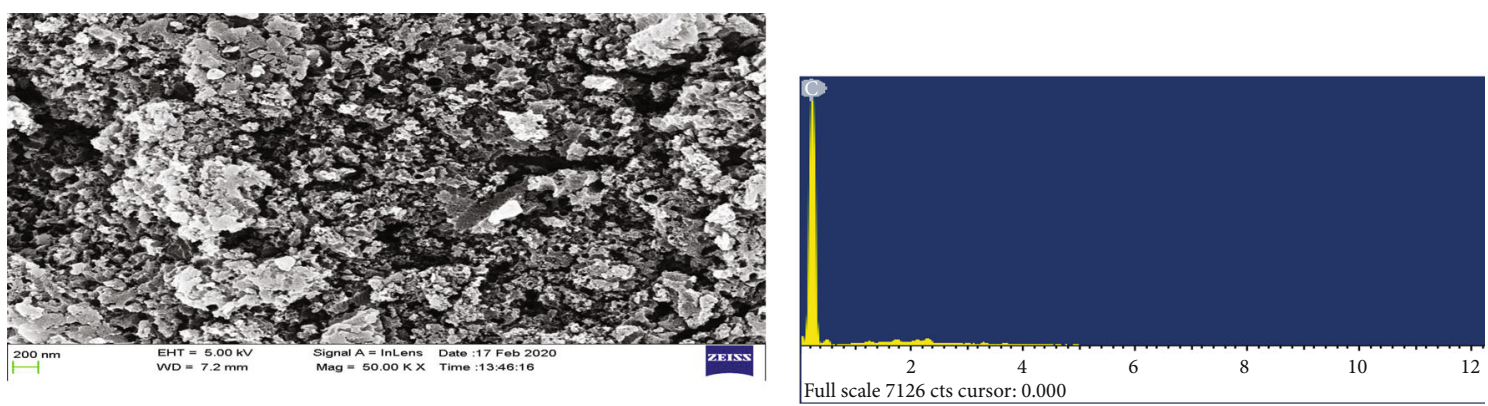

(a)
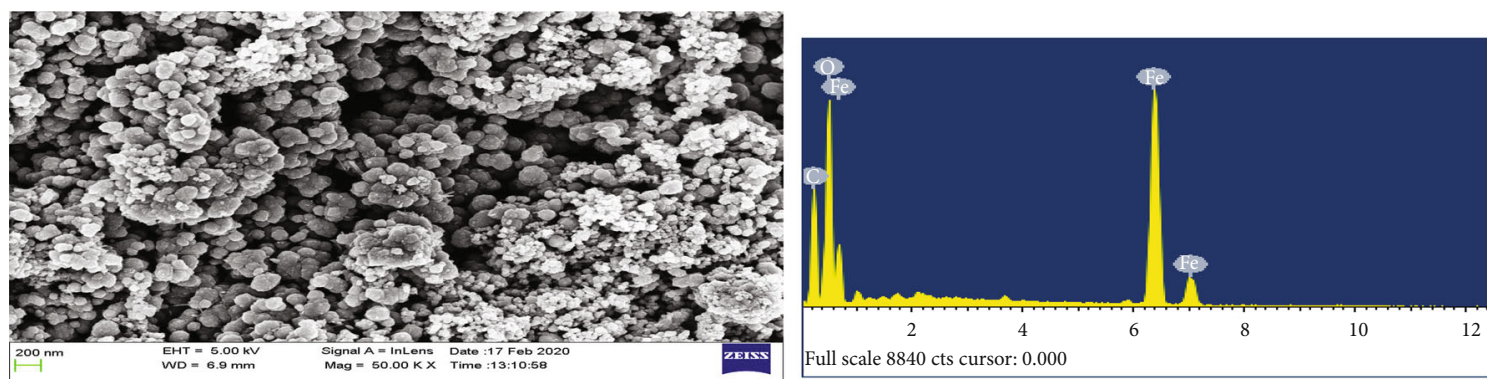

(b)

Figure 7: SEM-EDX. (a) Naked granular activated carbon (N-GAC) and (b) SPIONs impregnated granular activated carbon (Sp-GAC).

as hydrogen chromate $\left(\mathrm{HCrO}_{4^{-}}\right)$and dichromate ions $\left(\mathrm{Cr}_{2} \mathrm{O}_{72^{-}}\right)$of which dichromate ions are the predominant ratio of chromic anionic at low $\mathrm{pH}$ (as per the speciation report) [57]. And at acidic condition, the surface of adsorbent gets enriched with hydrogen ion, thereby acts as active positive charge site. This promotes electrostatic interaction between the adsorbent surface and anionic chromates which eventually turn out as the driving force for adsorption. This electrostatic force and the charge of the reacting components explained the principle of adsorption. As a contrary, in alkali $\mathrm{pH}$, the absorbent possesses negative charge due to abundant $-\mathrm{OH}$ which creates electric repulsion towards $\mathrm{Cr}(\mathrm{VI})$ anions. Here, at pH3, the adsorbents N-GAC and Sp-GAC are offered with more of $\mathrm{H}+$ ions which have supported the adsorption of anionic chromates. However, SPIONs are known to disintegrate at acidic $\mathrm{pH}$. $\mathrm{pH}$ was reduced, leading to increased iron discharge in high acidic $\mathrm{pH}(\mathrm{pH} 1)$.

3.4.2. Adsorption at different Adsorbent Concentration. Here, a fixed concentration of adsorbate $(\mathrm{Cr}(\mathrm{VI})$ at $5 \mathrm{ppm})$ is allowed to react with varied concentration of adsorbents N-GAC and Sp-GAC. Doing so, the maximum adsorbents required for complete removal are known. In each case, the iron leached was also estimated. The adsorption result is represented as a graph (Figure 12) with $X$-axis as adsorbent concentration $(\mathrm{g} / \mathrm{L})$, primary $Y$-axis as \% removal, and secondary $Y$-axis as iron leached (ppm). The resultant data clearly explained that the adsorption (\% removal of $\mathrm{Cr}(\mathrm{VI})$ ) increased with increase in concentration of the absorbent). This proved that efficiency of adsorption was dependent on the dosage of adsorbent used. Adsorption activity of $\mathrm{N}$ GAC and Sp-GAC was found to be similar which achieved $100 \%$ removal of $5 \mathrm{ppm} \mathrm{Cr}(\mathrm{VI})$ when $10 \mathrm{~g} / \mathrm{L}$ of each adsorbent was used. Therefore, the optimal concentration of adsorbent was fixed as $10 \mathrm{~g} / \mathrm{L}$. The better removal was shown by N-GAC due to the increased surface area but in case of Sp-GAC, availability of active sites might be low as SPIONs occupied the active sites of the granular activated carbon which did not allow way for the effective binding of chromium. Qureshi et al. [29] explained the adsorption of $\mathrm{Cr}(\mathrm{VI})$ by aluminium oxide and iron oxide impregnated carbon nanotubes. It was found that adsorption improved as the dosage of adsorbent was increased.

3.4.3. Adsorbate-Adsorbent Concentration. Here, a fixed concentration of adsorbent $(10 \mathrm{~g} / \mathrm{L})$ is allowed to react with varied concentration of adsorbate $-1 \mathrm{ppm}, 5 \mathrm{ppm}, 10 \mathrm{ppm}$, $20 \mathrm{ppm}, 40 \mathrm{ppm}, 80 \mathrm{ppm}, 160 \mathrm{ppm}$, and $320 \mathrm{ppm}$. Through this trial, the maximum efficiency of the adsorbent against the heavy metal Cr was identified. Also, the iron leached in each case was assessed. It was found that $10 \mathrm{~g} / \mathrm{L}$ of N-GAC showed 95.9\%, 99.9\%, 99.9\%, 99.45\%, 99.32\%, 98\%, $87.02 \%$, and $69.8 \%$ of $\mathrm{Cr}(\mathrm{VI})$ removal at $1 \mathrm{ppm}, 5 \mathrm{ppm}$, $10 \mathrm{ppm}, 20 \mathrm{ppm}, 40 \mathrm{ppm}, 80 \mathrm{ppm}, 160 \mathrm{ppm}$, and $320 \mathrm{ppm}$ whereas Sp-GAC removed maximum chromium of 99.7 , $89.6 \%, 84.6 \%, 74.11 \%, 74.37 \%, 62.8 \%$, and $40.09 \%$ and $23 \%$ at $1 \mathrm{ppm}, 5 \mathrm{ppm}, 10 \mathrm{ppm}, 20 \mathrm{ppm}, 40 \mathrm{ppm}, 80 \mathrm{ppm}$, $160 \mathrm{ppm}$, and $320 \mathrm{ppm}$, respectively (Figure 13). The performance of Sp-GAC greatly declined when $\mathrm{Cr}(\mathrm{VI})$ of high concentration was used. This manifested N-GAC as a better adsorbent material than Sp-GAC. This might be due to the increased surface area of the N-GAC and active sites available for binding of chromium to its surface. In Sp-GAC, the surface area is comparatively less due to which iron leach was high when higher concentration of chromium was used since there is no active site readily available for the adsorption reaction to take place. Also, N-GAC-treated samples showed total iron leach to $1.5 \mathrm{ppm}$ but Sp-GAC was found 


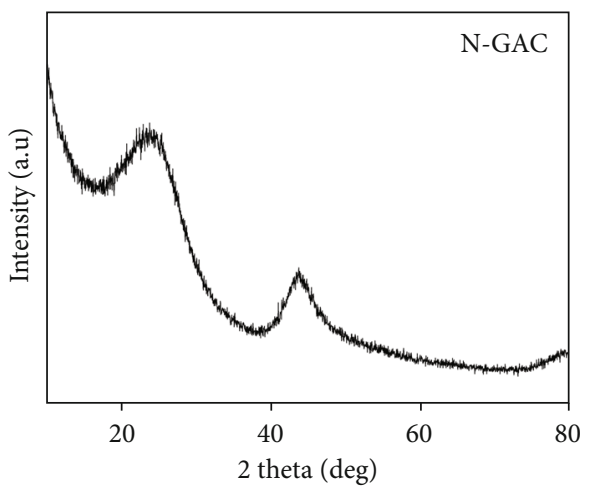

(a)

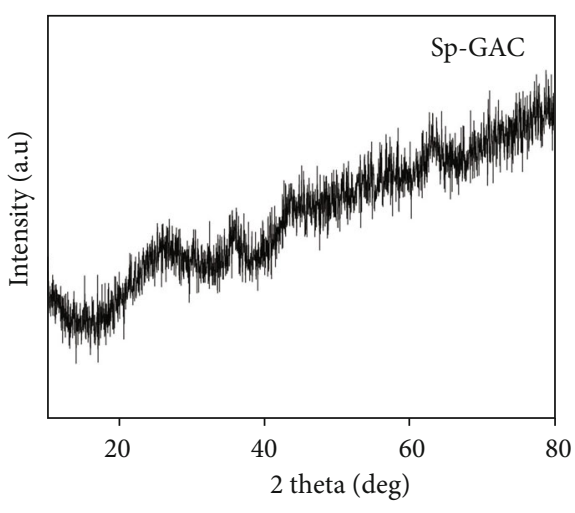

(b)

FIGURE 8: XRD. (a) Naked granular activated carbon (N-GAC) and (b) SPIONs impregnated granular activated carbon (Sp-GAC).

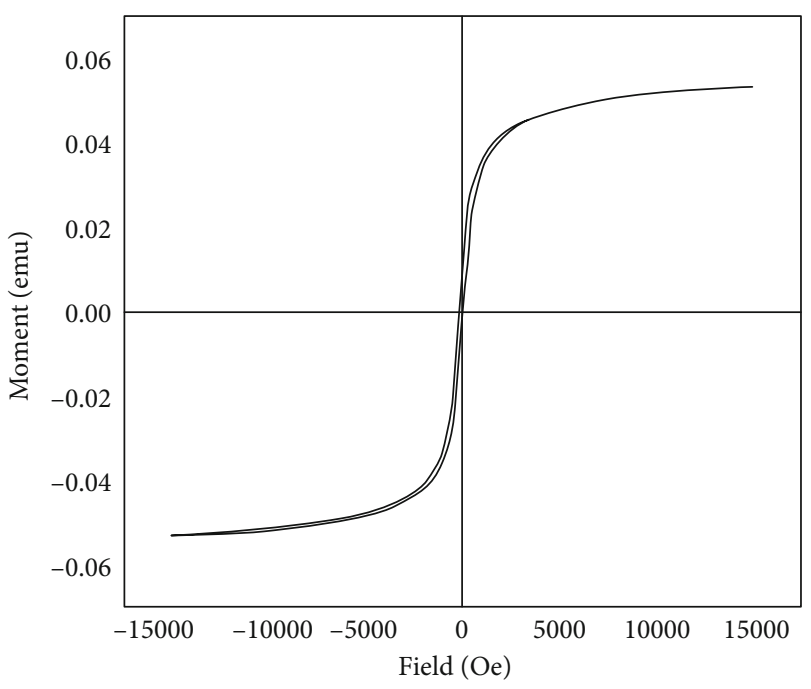

FIGURE 9: VSM of SPIONs impregnated granular activated carbon (Sp-GAC).

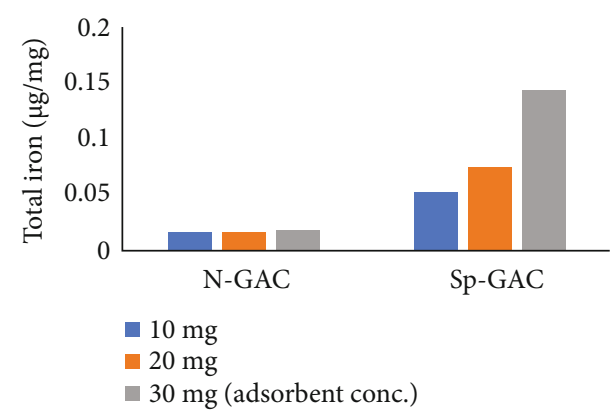

Figure 10: Quantification of iron. N-GAC: naked granular activated carbon; Sp-GAC: SPIONs impregnated granular activated carbon.

to leach more iron (2 ppm). Iron leaching could be ruled out by suitable functionalization or biopolymer coating. Under coexistent batch experiment [58], Cu(II) showed better affinity towards the magnetite (Fe3O4) nanoparticles than $\mathrm{Cr}(\mathrm{VI})$. It was also noticed that the removal rates of both the metal ions $(\mathrm{Cr}(\mathrm{VI})$ and $\mathrm{Cu}(\mathrm{II}))$ depreciated when the initial concentration of the adsorbates was increased.
3.5. Adsorption Isotherm. The adsorption of $\mathrm{Cr}(\mathrm{VI})$ in the batch system was analysed by applying the adsorption isotherm models like Langmuir, Freundlich, and Temkin. The correlation coefficient $\left(R^{2}\right)$ from each case were compared, and the isotherm with highest $R^{2}$ value was considered as the best fit model. N-GAC responded to Langmuir, Freundlich, and Temkin isotherms with $R^{2}=0.37,0.70$, and 0.44 , respectively (Figure 14). Likewise, Sp-GAC showed $R^{2}$ values as $0.57,0.64$, and 0.44 correspondingly (Figure 14 ). In both cases, $R^{2}$ of Freundlich isotherm were greater than 0.6. Therefore, it can be assumed that adsorption reaction between the adsorbent and adsorbate abide by the Freundlich isotherm model. This described the adsorption mechanism as multilayered and homogenous. $\mathrm{Cr}$ (VI) adsorption by differently processed activated carbon from Tuncbilek lignite was reported to be influenced by factors like $\mathrm{pH}$, temperature, and initial adsorbate concentration [59]. The activated carbon produced by physical methods showed better adsorption (95\% of Cr removal at $563 \mathrm{ppm}$ ), and it followed Langmuir adsorption principle.

\section{Conclusion}

By following chemical coprecipitation method, SPIONs impregnated activated carbon (Sp-GAC) were produced and characterized. SEM micrograph portrayed the pattern of impregnation in Sp-GAC, where the surface of activated carbon was found to be covered with SPIONs. FT-IR and EDX confirmed the impregnation of SPIONs on activated carbon whose superparamagnetic property was identified through VSM. XRD spectra confirmed the amorphic nature of carbon (N-GAC) whereas impregnated carbon (Sp-GAC) was found to be slightly crystalline. On utilizing N-GAC and Sp-GAC in adsorption of $\operatorname{Cr}(\mathrm{VI})$, it was found that the adsorption was phenomenally influenced by the $\mathrm{pH}$ of the treating solution. Better adsorption was noticed at $\mathrm{pH}$ 3. Further adsorption study revealed that N-GAC showed better adsorption to Sp-GAC at increased $\mathrm{Cr}(\mathrm{VI})$ concentration. Hence, it can be concluded that the SPION impregnation on to carbon has not much influence on $\mathrm{Cr}(\mathrm{VI})$ removal in batch system. 


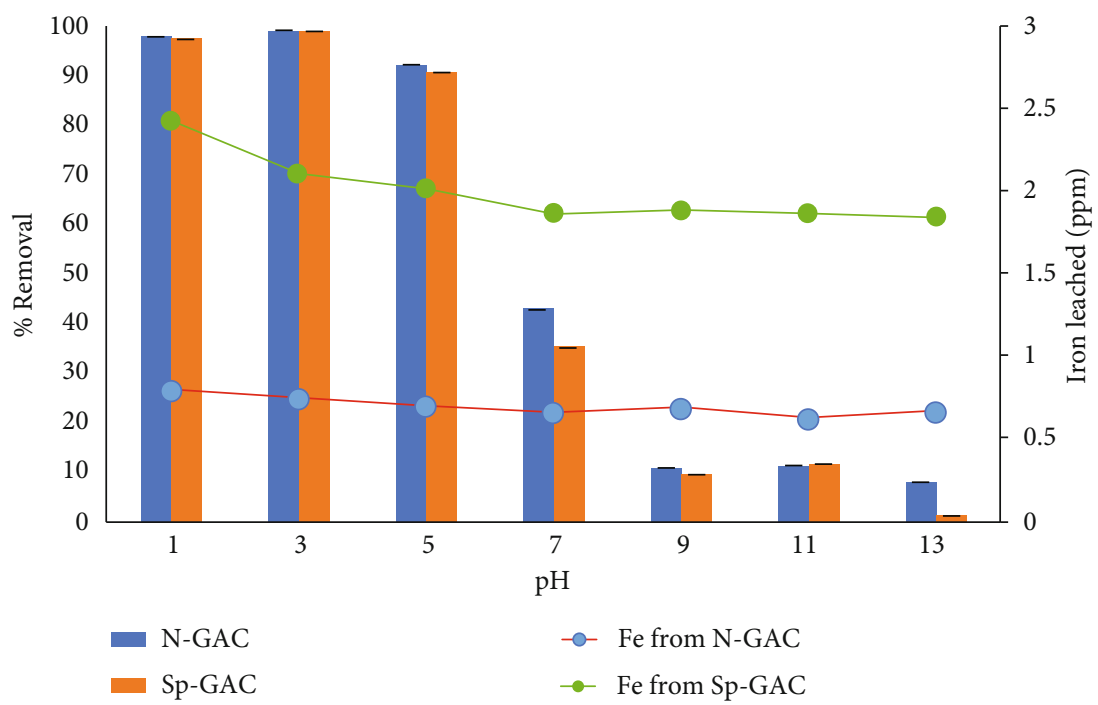

FIgURe 11: Adsorption of N-GAC and Sp-GAC at various pH. N-GAC: naked granular activated carbon; Sp-GAC: SPIONs impregnated granular activated carbon.

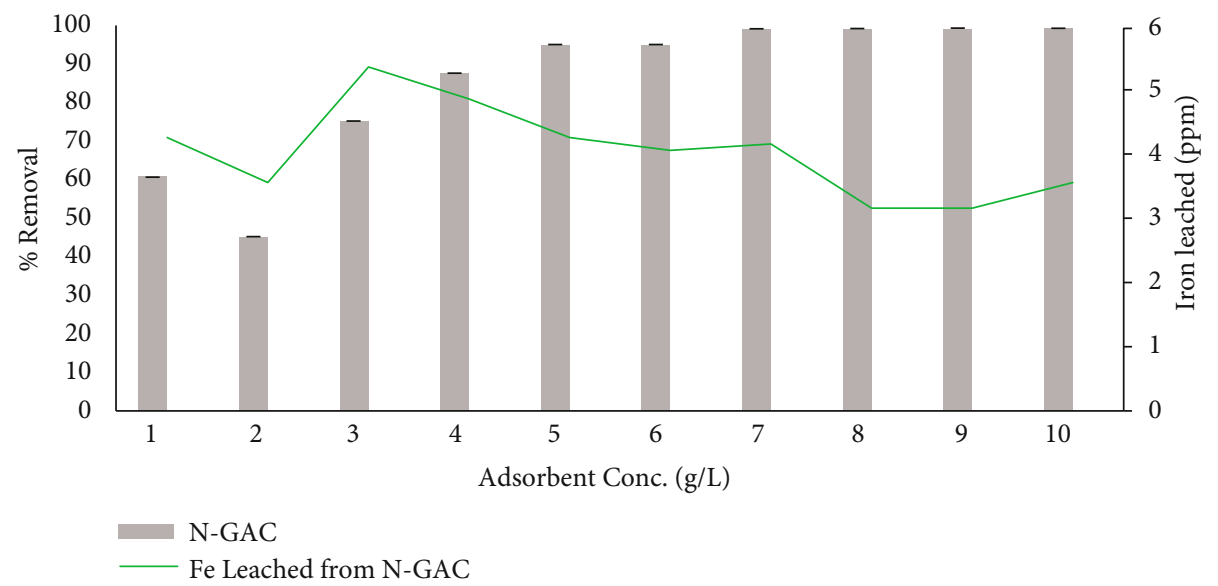

(a)

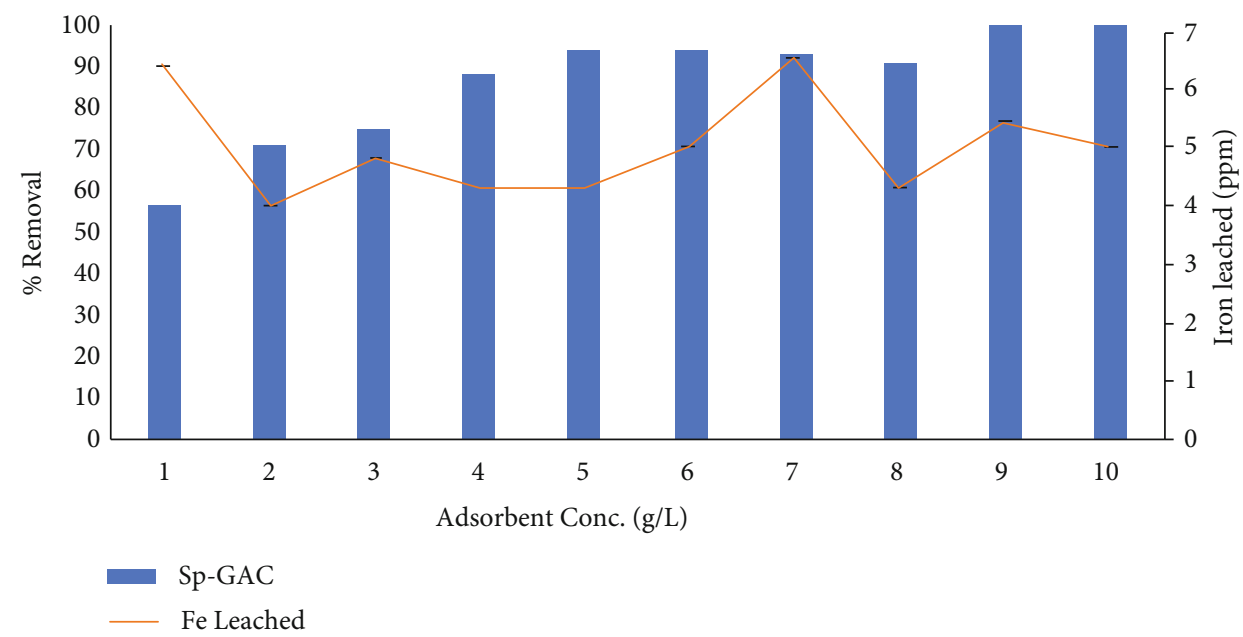

(b)

FIGURE 12: Determination of adsorbate-adsorbent concentration. (a) N-GAC: naked granular activated carbon and (b) Sp-GAC: SPIONs impregnated granular activated carbon. 


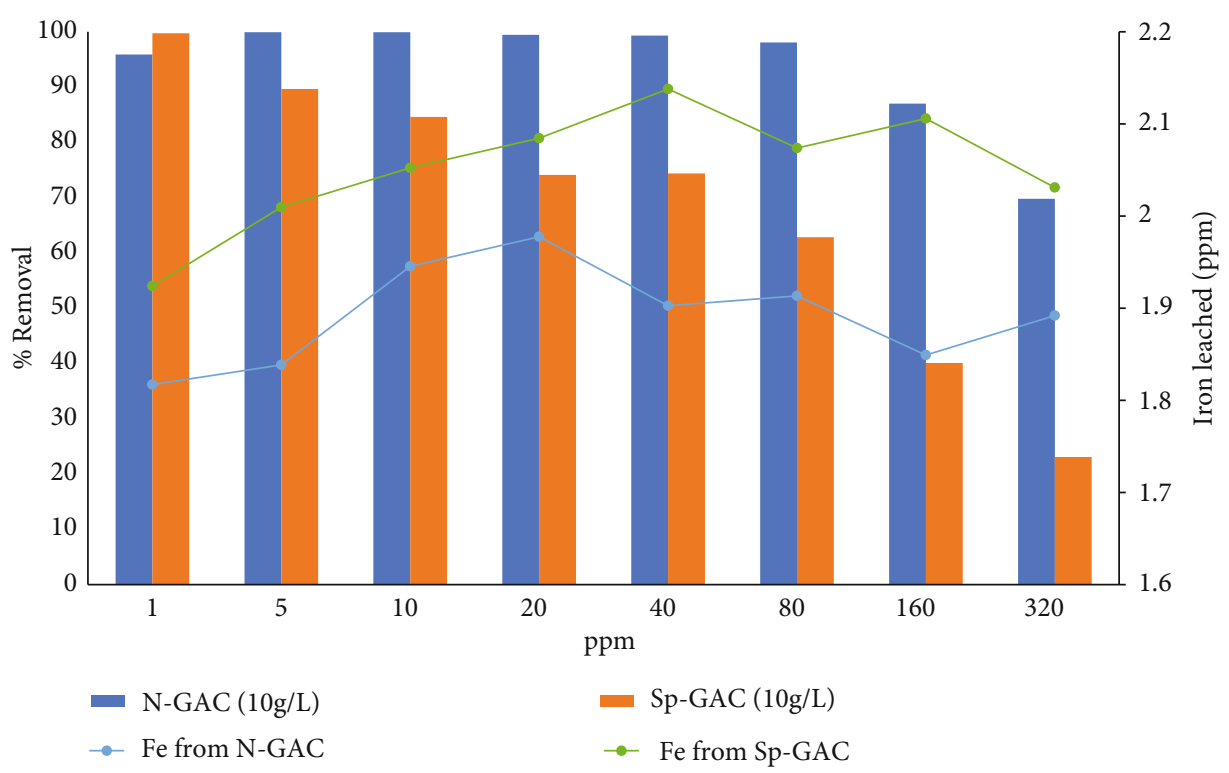

FIGURE 13: Adsorption as a function of adsorbate-adsorbent concentration. N-GAC: naked granular activated carbon; Sp-GAC: SPIONs impregnated granular activated carbon.

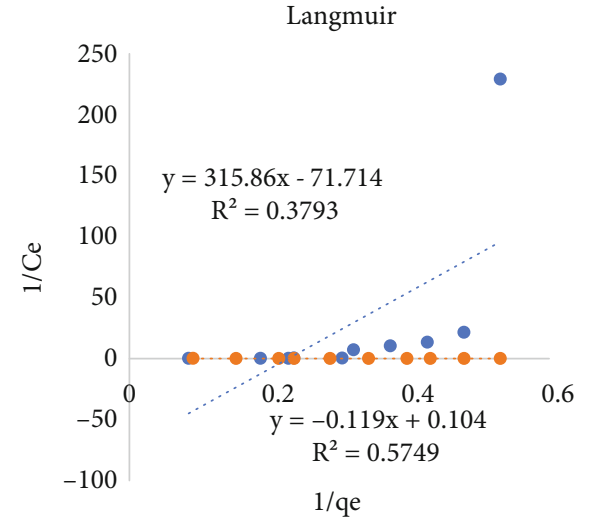

(a)

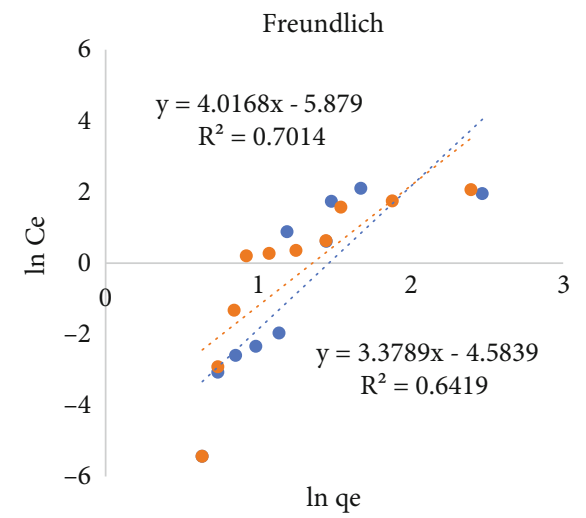

(b)

Temkin

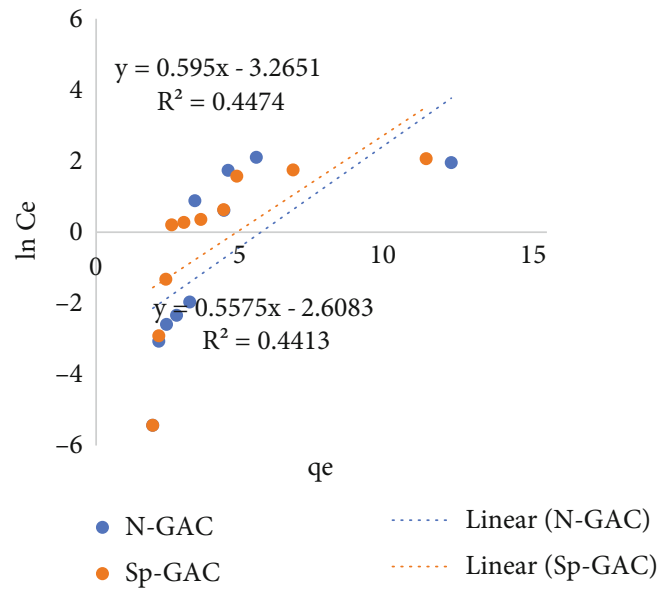

(c)

FIGURE 14: Adsorption isotherm. (a) Langmuir isotherm, (b) Freundlich isotherm, and (c) Temkin isotherm. 


\section{Data Availability}

The datasets used and analysed during the present study are available from the corresponding author on reasonable request.

\section{Conflicts of Interest}

The authors declare no conflict of interest.

\section{Acknowledgments}

The authors extend their appreciation to the Deputyship for Research and Innovation, Ministry of Education, Saudi Arabia, for funding this research work through the project number 375213500. The authors acknowledge the Central Laboratory at Jouf University, Saudi Arabia.

\section{References}

[1] A. Ertani, A. Mietto, M. Borin, and S. Nardi, "Chromium in agricultural soils and crops: A review," Water, Air, \& Soil Pollution, vol. 228, no. 5, 2017.

[2] M. Litaay, R. V. Jehadum, R. Mardaranti, and E. Soekendarsi, "The heavy metals lead $(\mathrm{Pb})$, chromium $(\mathrm{Cr})$, copper $(\mathrm{Cu})$ and cadmium (Sd) contents in the white shellMeretrix meretrixLinnaeus, 1758," Journal of Physics Conference Series, vol. 1116, article 052039, 2018.

[3] J. A. Izbicki, M. T. Wright, W. A. Seymour et al., "Cr(VI) occurrence and geochemistry in water from public-supply wells in California," Journal of Applied Geochemistry, vol. 2015, no. 63, pp. 203-217, 2015.

[4] A. Vengosh, R. Coyte, J. Karr et al., "Origin of hexavalent chromium in drinking water wells from the piedmont aquifers of North Carolina," Environmental Science \& Technology Letters, vol. 3, no. 12, pp. 409-414, 2016.

[5] J. K. Dennis and T. E. Such, Nickel and Chromium Plating, Woodhead Publishing Series in Metals and Surface Engineering, 1993.

[6] G. A. Engwa, P. U. Ferdinand, F. N. Nwalo, and M. N. Unachukwu, "Mechanism and Health Effects of Heavy Metal Toxicity in Humans," in Poisoning in the Modern World-New Tricks for an Old Dog?, IntechOpen, 2019.

[7] D. C. Adriano, "Chromium," in Trace Elements in Terrestrial Environments, pp. 315-348, Springer, 2001.

[8] H. Oliveira, "Chromium as an environmental pollutant: insights on induced plant toxicity," Journal of Botany, vol. 18, 2012.

[9] Y. Wang, H. Su, Y. Gu, X. Song, and J. Zhao, "Carcinogenicity of chromium and chemoprevention: a brief update," Oncotargets and Therapy, vol. 10, no. 10, pp. 4065-4079, 2017.

[10] H. Sun, J. Brocato, and M. Costa, "Oral chromium exposure and toxicity," Current Environmental Health Reports, vol. 2, no. 3, pp. 295-303, 2015.

[11] S. J. Stohs and D. Bagchi, "Oxidative mechanisms in the toxicity of metal ions," Free Radical Biology \& Medicine, vol. 18, no. 2, pp. 321-336, 1995.

[12] M. Jaishankar, T. Tseten, N. Anbalagan, B. B. Mathew, and K. N. Beeregowda, "Toxicity, mechanism and health effects of some heavy metals," Interdisciplinary Toxicology, vol. 7, no. 2 , pp. $60-72,2014$.
[13] F. Minas, B. S. Chandravanshi, and S. Leta, "Chemical precipitation method for chromium removal and its recovery from tannery wastewater in Ethiopia," Chemistry International, vol. 3, no. 4, pp. 392-405, 2017.

[14] A. Alemu, B. Lemma, and N. Gabbiye, "Adsorption of chromium (III) from aqueous solution using vesicular basalt rock," Cogent Environmental Science, vol. 5, no. 1, article 1650416, 2019.

[15] M. N. Rao, R. Sultana, and S. H. Kota, "Hazardous Waste," in Solid and Hazardous Waste Management, pp. 159-207, Elsevier, 2017.

[16] H. Peng, Y. Leng, Q. Cheng, Q. Shang, J. Shu, and J. Guo, "Efficient removal of hexavalent chromium from wastewater with electro-reduction," Processes, vol. 7, no. 1, 2019.

[17] A. Mnif, I. Bejaoui, M. Mouelhi, and B. Hamrouni, "Hexavalent chromium removal from model water and car shock absorber factory effluent by nanofiltration and reverse osmosis membrane," International Journal of Analytical Chemistry, vol. 2017, Article ID 7415708, 10 pages, 2017.

[18] S. S. Baral, S. N. Das, and P. Rath, "Hexavalent chromium removal from aqueous solution by adsorption on treated sawdust," Biochemical Engineering Journal, vol. 31, no. 3, pp. 216222, 2006.

[19] N. Itankar and Y. Patil, "Management of hexavalent chromium from industrial waste using low-cost waste biomass," Procedia-Social and Behavioral Sciences, vol. 133, pp. 219224, 2014

[20] A. V. Samrot, J. L. A. Angalene, S. M. Roshini et al., "Bioactivity and heavy metal removal using plant gum mediated green synthesized silver nanoparticles," Journal of Cluster Science, vol. 30, no. 6, pp. 1599-1610, 2019.

[21] S. Parlayici, V. Eskizeybek, A. Avc1, and E. Pehlivan, "Removal of chromium (VI) using activated carbon-supportedfunctionalized carbon nanotubes," Journal of Nanostructure in Chemistry, vol. 5, no. 3, pp. 255-263, 2015.

[22] C. Justin, A. V. Samrot, P. D. Sruthi, C. S. Sahithya, K. S. Bhavya, and C. Saipriya, "Preparation, characterization and utilization of coreshell super paramagnetic iron oxide nanoparticles for curcumin delivery," vol. 13, no. 7, Article ID e0200440, 2018.

[23] P. O. Champagne, H. Westwick, A. Bouthillier, and M. Sawan, "Colloidal stability of superparamagnetic iron oxide nanoparticles in the central nervous system: a review," Nanomedicine, vol. 13, no. 11, pp. 1385-1400, 2018.

[24] D. Lachowicz, A. Kaczyńska, R. Wirecka et al., "A hybrid system for magnetic hyperthermia and drug delivery: SPION functionalized by curcumin conjugate," Materials, vol. 11, no. 12,2018

[25] M. Mahmoudi, M. A. Sahraian, M. A. Shokrgozar, and S. Laurent, "Superparamagnetic iron oxide nanoparticles: promises for diagnosis and treatment of multiple sclerosis," ACS Chemical Neuroscience, vol. 2, no. 3, pp. 118-140, 2011.

[26] E. Kuchma, S. Kubrin, and A. Soldatov, "The local atomic structure of colloidal superparamagnetic iron oxide nanoparticles for theranostics in oncology," Biomedicine, vol. 6, no. 3, 2018.

[27] M. Khalkhali, K. Rostamizadeh, S. Sadighian, F. Khoeini, M. Naghibi, and M. Hamidi, "The impact of polymer coatings on magnetite nanoparticles performance as MRI contrast agents: a comparative study," DARU Journal of Pharmaceutical Sciences, vol. 23, no. 1, 2015. 
[28] J. Hong, J. Xie, S. Mirshahghassemi, and J. Lead, "Metal (Cd, $\mathrm{Cr}, \mathrm{Ni}, \mathrm{Pb}$ ) removal from environmentally relevant waters using polyvinylpyrrolidone-coated magnetite nanoparticles," RSC Advances, vol. 10, no. 6, pp. 3266-3276, 2020.

[29] M. I. Qureshi, F. Patel, N. Al-Baghli, B. Abussaud, B. S. Tawabini, and T. Laoui, "A comparative study of raw and metal oxide impregnated carbon nanotubes for the adsorption of hexavalent chromium from aqueous solution," Bioinorganic Chemistry and Applications, vol. 2017, Article ID 1624243, 10 pages, 2017.

[30] M. Jain, M. Yadav, T. Kohout, M. Lahtinen, V. K. Garg, and M. Sillanpää, "Development of iron oxide/activated carbon nanoparticle composite for the removal of $\mathrm{Cr}(\mathrm{VI}), \mathrm{Cu}(\mathrm{II})$ and $\mathrm{Cd}(\mathrm{II})$ ions from aqueous solution," Water Resources and Industry, vol. 20, pp. 54-74, 2018.

[31] A. V. Samrot, C. S. Sahithya, A. J. Selvarani, S. Pachiyappan, and S. S. Kumar, "Surface-engineered super-paramagnetic iron oxide nanoparticles for chromium removal," International Journal of Nanomedicine, vol. 14, pp. 8105-8119, 2019.

[32] J. Changzhao, Y. G. Siyu, P. H. Neng, and L. Hong, "A method for determination of $[\mathrm{Fe} 3+] /[\mathrm{Fe} 2+]$ ratio in superparamagnetic iron oxide," Journal of Magnetism and Magnetic Materials, vol. 439, 2017.

[33] K. K. Onchoke and S. A. Sasu, "Determination of hexavalent chromium $(\mathrm{Cr}(\mathrm{VI}))$ concentrations via ion chromatography and UV-vis spectrophotometry in samples collected from Nacogdoches Wastewater Treatment Plant, East Texas (USA)," Advances in Environmental Chemistry, vol. 2016, Article ID 3468635, 10 pages, 2016.

[34] T. Shigematsu, S. Gohda, H. Yamazaki, and Y. Nishikawa, "Spectrophotometric determination of chromium (III) and chromium (VI) in sea water," Bulletin of the Institute for Chemical Research, Kyoto University, vol. 55, no. 5, pp. 429440, 1978.

[35] N. Ayawei, A. N. Ebelegi, and D. Wankasi, "Modelling and interpretation of adsorption isotherms," Journal of Chemistry, vol. 2017, Article ID 3039817, 11 pages, 2017.

[36] J. S. Duque, B. M. Madrigal, H. Riascos, and Y. P. Avila, "Colloidal metal oxide nanoparticles prepared by laser ablation technique and their antibacterial test," Colloids Interfaces, vol. 3, no. 1, p. 25, 2019.

[37] C. Justin, S. A. Philip, and A. V. Samrot, "Synthesis and characterization of superparamagnetic iron-oxide nanoparticles (SPIONs) and utilization of SPIONs in X-ray imaging," Applied Nanoscience, vol. 7, no. 7, pp. 463-475, 2017.

[38] A. V. Samrot, C. Sai Priya, A. J. Selvarani et al., "A study on influence of superparamagnetic iron oxide nanoparticles (SPIONs) on green gram (Vigna radiata L.) and earthworm (Eudrilus eugeniae L.)," Materials Research Express, vol. 7, no. 5, article 055002, 2020.

[39] G. Marco, G. Andrea, C. Silvia et al., "Superparamagnetic iron oxide nanoparticles functionalized by peptide nucleic acids," RSC Advances, vol. 7, no. 25, pp. 15500-15512, 2017.

[40] B. Lesiak, N. Rangam, P. Jiricek et al., "Surface study of Fe3O4 nanoparticles functionalized with biocompatible adsorbed molecules," Frontiers in Chemistry, vol. 7, 2019.

[41] A. V. Samrot, P. Senthilkumar, S. Rashmitha, P. Veera, and C. S. Sahithya, "Azadirachta indica influenced biosynthesis of super-paramagnetic iron-oxide nanoparticles and their applications in tannery water treatment and X-ray imaging," Journal of Nanostructure in Chemistry, vol. 8, no. 3, pp. 343-351, 2018.
[42] A. V. Samrot, N. Shobana, P. Durga Sruthi, and C. S. Sahithya, "Utilization of chitosan-coated superparamagnetic iron oxide nanoparticles for chromium removal," Applied Water Science, vol. 8, no. 7, 2018.

[43] J. D. Litewka, A. Łazarczyk, P. Hałubiec, O. Szafranski, K. Karnas, and A. Karewicz, "Superparamagnetic iron oxide nanoparticles - current and prospective medical applications," Maternité, vol. 12, 2019.

[44] P. D. Sruthi, C. S. Sahithya, C. Justin et al., "Utilization of chemically synthesized super paramagnetic iron oxide nanoparticles in drug delivery, imaging and heavy metal removal," Journal of Cluster Science, vol. 30, no. 1, 2019.

[45] V. A. J. Silva, P. L. Andrade, M. P. C. Silva, D. A. Bustamante, L. De Los Santos Valladares, and J. Albino Aguiar, "Synthesis and characterization of $\mathrm{Fe} 3 \mathrm{O} 4$ nanoparticles coated with fucan polysaccharides," Journal of Magnetism and Magnetic Materials, vol. 343, pp. 138-143, 2013.

[46] J. Chellapan, A. V. Samrot, A. A. Annamalai, R. Bhattacharya, P. Sathiyamoorthy, and C. S. Sahithya, "Biopolymer coated coreshell magnetite nanoparticles for rifampicin delivery," Oriental Journal of Chemistry, vol. 34, no. 5, 2018.

[47] S. Prijic, J. Scancar, R. Romih et al., "Increased cellular uptake of biocompatible superparamagnetic iron oxide nanoparticles into malignant cells by an external magnetic field," The Journal of Membrane Biology, vol. 236, no. 1, pp. 167-179, 2010.

[48] A. G. Kolhatkar, A. C. Jamison, D. Litvinov, R. C. Willson, and T. R. Lee, "Tuning the magnetic properties of nanoparticles," International Journal of Molecular Sciences, vol. 14, no. 8, pp. 15977-16009, 2013.

[49] A. Baykal, M. Amir, S. Günerb, and H. Sözeri, "Preparation and characterization of SPION functionalized via caffeic acid," Journal of Magnetism and Magnetic Materials, vol. 395, pp. 199-204, 2015.

[50] A. A. Attia, S. A. Khedr, and S. A. Elkholy, "Adsorption of chromium ion (vi) by acid activated carbon," Brazilian Journal of Chemical Engineering, vol. 27, no. 1, pp. 183-193, 2010.

[51] J. C. Matos, M. C. Gonçalves, L. C. J. Pereira, B. J. C. Vieira, and J. C. Waerenborgh, "SPIONs prepared in air through improved synthesis methodology: the influence of $\gamma$-Fe2O3/ $\mathrm{Fe} 3 \mathrm{O} 4$ ratio and coating composition on magnetic properties," Nanomaterials, vol. 9, no. 7, p. 943, 2019.

[52] A. B. Rajendran, G. Manivannan, K. Jothivenkatachalam, and S. Karthikeyan, "Characterization studies of activated carbon from low cost agricultural waste: Leucaena leucocephala seed shell, Rasayan. J," Journal of Chemistry, vol. 8, no. 3, pp. 330-338, 2015.

[53] C. N. Tejada, D. Almanza, A. Villabona, F. Colpas, and C. Granados, "Characterization of activated carbon synthesized at low temperature from cocoa shell (Theobroma cacao) for adsorbing amoxicillin," Ingeniería Y Competitividad, vol. 19, no. 2, pp. 45-54, 2017.

[54] G. Gallios, A. Tolkou, I. Katsoyiannis, K. Stefusova, M. Vaclavikova, and E. Deliyanni, "Adsorption of arsenate by nano scaled activated carbon modified by iron and manganese oxides," Sustainability, vol. 9, no. 10, 2017.

[55] A. Szpak, G. Kania, T. Skórka, W. Tokarz, S. Zapotoczny, and M. Nowakowska, "Stable aqueous dispersion of superparamagnetic iron oxide nanoparticles protected by charged chitosan derivatives," Journal of Nanoparticle Research, vol. 15, no. 1,2013 . 
[56] W. Górka, T. Kuciel, P. Nalepa, D. Lachowicz, S. Zapotoczny, and M. Szuwarzyński, "Homogeneous embedding of magnetic nanoparticles into polymer brushes during simultaneous surface-initiated polymerization," Nanomaterials, vol. 9, no. 3, p. 456, 2019.

[57] R. Rakhunde, L. Deshpande, and H. D. Juneja, "Chemical speciation of chromium in water: a review," Critical Reviews in Environmental Science and Technology, vol. 42, no. 7, pp. 776-810, 2012.

[58] J. Zhang, S. Lin, M. Han, Q. Su, L. Xia, and Z. Hui, “Adsorption properties of magnetic magnetite nanoparticle for coexistent $\mathrm{Cr}(\mathrm{VI})$ and $\mathrm{Cu}(\mathrm{II})$ in mixed solution," Water, vol. 12 , no. 2 , 2020.

[59] R. Yavuz, I. Orbak, and N. Karatepe, "Factors affecting the adsorption of chromium (VI) on activated carbon," Journal of Environmental Science and Health, Part A, vol. 41, no. 9, pp. 1967-1980, 2006. 